\title{
New Perspectives in Teaching and Learning: Reforms or Educational Revolution?
}

\author{
Draginja Jeftic
}

Faculty of Philosophy, University of Montenegro N. Bojovica, bb. Niksic, 81400

\author{
Doi:10.5901/jesr.2014.v4n4p60
}

Although all disciplines, including education, have experienced large-scale transformations during the last several decades owing to remarkable scientific development, in many instances, current practices in education still reflect the philosophy and standards of the mass production model which was a direct product of the Industrial Revolution. Namely, in order to educate as many children as possible in a short period of time, children were grouped into classes according to their age and not their abilities, needs, learning styles and social backgrounds; all learners in a particular class were exposed to the same curriculum and taught on a one subject-one lesson basis by teachers who usually specialized in one specific subject area. Today, many decades later, learners are basically still placed in classes according to age, are exposed to a curriculum that does not always successfully prepare them for the future workforce and are taught by teachers who often specialize in only one subject area, thus depriving learners of full exposure to the needs of the twentyfirst century, that is, interdisciplinary, collaborative task-based project work.

All things considered, education throughout the world is still characterized by artificial barriers to learning; for example, holding lessons within the four walls of classrooms, using a bell system to denote the end of one subject/class and the beginning of the next subject/class, utilizing content-driven curricula based on the philosophy of one-size-fits-all classroom instruction. With the explosion of information in the fields of science and technology, professionals in education recognize the dramatic changes that have occurred during the last few decades, and acknowledge that a new insight into teaching and learning has developed.

Contemporary teaching practices in the classroom are very different to the methods of instruction utilized in past decades; twenty-first century teaching is centred on a completely different approach to the understanding of the learning process, and thus also, to the choice of accompanying classroom activities. Information gathered from multidisciplinary scientific research in the field of education has contributed significantly towards understanding the processes involved in acquisition of knowledge and skills. The pedagogical branch of neuroscience has offered educators essential information regarding the learners' preferred cognitive path in acquisition of knowledge and skills, and how teachers can offer the most effective scaffolding in order to maximize the learners' capacity to acquire knowledge, learning strategies and skills.

The above-mentioned unique challenges have made a great impact in the field of education and have launched a remarkable transformation in the classroom; not only are educators and learners required to take on new roles in the classroom, but also, the whole classroom environment has been channeled in the direction of the development of cooperative, collaborative learning communities.

Transformation in the contemporary classroom extends beyond mere reforms of existing teaching and learning methods or modernization of teaching/learning materials and techniques to embrace the dynamism of a revolution in education that includes empowering learners to self-invest in their education and the reconstruction of classroom strategies to meet these new perspectives. This new rationale for education recognizes learners and teachers as colearners in a learning community that is based on shared teacher-learner responsibilities in settings that spread beyond the classroom walls and the school to include authentic learner experiences, often in the workplace, itself. Education systems that are contingent on learner uniformity, learner conformity and learner compliance are being replaced by systems that personalize education rather than customize education, that teach the learner and not the discipline, in other words, that meet the needs of the future. The development of transferable learner strategies, critical/reflective/rational thinking skills, creativity, leadership qualities including perseverance, collaboration, problem-solving skills, effective communication and conflict resolution skills, together with growth of global awareness and media literacy, highlight twenty-first century education.

\section{New Roles of the Teacher and the Learner}

As a result of new perspectives on standard occurrences in the classroom, teachers are required to re-examine their teaching strategies and learner expectations. The contemporary educational scene focuses on learner-centered 
pedagogy which is established upon the merits and principles of learner autonomy. Holec (1981) defined autonomy as 'the ability to take charge of one's own learning' (p. 3) Learner autonomy in the classroom necessitates an extension of the role of the teacher to incorporate teaching to the multiple intelligences of the learners and developing differentiated programs of instruction, accordingly. Autonomous learners recognize their own learning styles and study strategies, are able to formulate aims and objectives of their tasks, take an active, thorough and meaningful approach to their learning experiences, are willing reflect, self-assess, revise and reject unsatisfactory work, are able to monitor their work and ask for help when necessary, and are totally committed to their studies.

In light of these dramatic educational developments, teachers need to expose learners to a range of transferable skills, both cognitive and metacognitive, to facilitate enhanced learning. All astute teachers teach cognitive strategies such as repetition, in order to place the target information into long-term memory, resourcing, to be able to access and effectively utilize appropriate resources for studies, meaningful note-taking, increasing powers of deduction, for example, conscious application of rules, encouraging interdisciplinary transfer of knowledge, the skills of inferencing, recognizing main ideas, questioning for clarification, etc. Cognitive skills also comprise working independently on some tasks and activities, communicating clearly, interactively and logically, implementing self-discipline in group work, scanning and skimming through texts, summarizing, effective researching, categorizing, and comparing and contrasting. Superior teachers go beyond cognitive skills to include the skills and strategies that are necessary for learners to gain total ownership of their learning, the so-called metacognitive strategies. Metacognitive strategies are actually strategies about learning, or more precisely, learning how to learn and self-investing in one's own studies; these strategies are the tools learners utilize in order to identify their aims and objectives so as to create a plan for an activity/task/project at the initial stage, to continuously monitor progress for the duration of the activity/task/project, and to reflect upon and evaluate the completed outcome of the learning activity/task/project, typically using a set of standard criteria. As maintained by Wenden (1998: 34), 'metacognitive knowledge includes all facts learners acquire about their own cognitive processes as they are applied and used to gain knowledge and acquire skills in varied situations'.

Mastery of metacognitive strategies for successful learning is an essential component of all contemporary classrooms; learners are required to master a set of strategies and approaches to learning in order to function successfully in the classroom. Enlightened learners need to be able to define the aims and objectives of a lesson, activity or project, to be able to choose, judge and reflect on suitable resources such as literature, textbooks, etc., and, to know how to access libraries and computer material. Subsequent to identifying task/project requirements and determining performance evaluation, learners must master and consciously utilize the important metacognitive strategies of planning, monitoring and reflecting. This includes creating a workable timeline or schedule in order to be able to estimate the time required to complete a task or project and set priorities, making an appropriate checklist, organizing materials, and using strategies such as outlining, graphic organizers, and having the ability to organize an activity and to link it to previously mastered knowledge or skill etc. Finally, reflecting on the learning process, keeping track of successful strategies and monitoring one's own learning by asking for help when necessary, and self-evaluating using appropriate rubrics, are all metacognitive strategies that help develop autonomy in the classroom.

Twenty-first century modifications in education include teaching learners the skills, attitudes and procedures necessary for successful studies. Effective management of learning also encompasses mastering approaches to learning. For example, learners need to develop study and organizational skills, time and stress-management skills, meaningful classroom cooperation and collaboration, powerful oral and written communication, the ability to make rational judgments using a variety of resources, reasoning/higher-order thinking skills, an effective level of information literacy, active listening skills, powers of reflection, problem-solving skills, and interdisciplinary understanding and connections.

As this innovative, more meaningful paradigm in education emerges, professionals in this field are faced with the question of how these historical changes can be realized in the classroom. Perhaps, these changes are most successfully put into effect in classrooms by providing learners with the necessary tools that allow them to be in control of their learning, that is, their experiences at school, from the earliest age possible. An important step in this quest is for learner-centered acquisition of knowledge and skills to be associated with constructivist learning theory which changes education from the transfer of knowledge from teacher-to-student to the construction of knowledge by learners who receive appropriate support at the right moments by an educator or even a knowledgeable peer. Problem/task- based learning projects are excellent examples of interactive and experiential learner-centered acquisition of knowledge and skills. In such learner-centered environments, learners are encouraged to participate in defining their own learning goals/objectives and designing their personal project-assessment rubrics. Obviously, learners need to be introduced to and become familiar with the expectations and standards required in such learning experiences; similarly, development of learner self-direction and learner self-monitoring is a necessary element in classroom strategies of the twenty-first century. Learners play a more active and responsible role in their own learning; they learn to collaborate and 
communicate successfully, develop more natural, lifelong learning skills, and explore self-regulation and self-determinism in activities that effectively contribute to their learning experiences. Lea et al. (2003:322) summarizes some of the literature on learner-centred learning to include the following:

1. 'the reliance on active rather than passive learning,

2. an emphasis on deep learning and understanding,

3. increased responsibility and accountability on the part of the student,

4. an increased sense of autonomy in the learner

5. an interdependence between teacher and learner,

6. mutual respect within the learner teacher relationship,

7. and a reflexive approach to the teaching and learning process on the part of both teacher and learner.'

In short, as society and expectations are constantly being modified by developments in science, education must keep abreast of these changes in order to help transform traditional, institutionalized learning into a more personalized, authentic, meaningful experience.

A new rationale of education emerges in light of these developments. Learners and teachers become co-learners with shared responsibilities in the learning community. Negotiation strategies become a part of the classroom scene.

Teachers use negotiation strategies with learners in order to:

- make decisions on topics of research/projects

- determine the aims and objectives of the chosen project

- create well-balanced time-lines for completion of the project

- decide upon the style of presentation of the project

- choose the type of assessment for the project

- create rubrics for the different stages of the project, etc.

With the purpose of providing further insight into twenty-first century learning and teaching, it is essential to view the teachers' and learners' new, comprehensive roles in the classroom and to present crucial learning strategies and facts that empower and support the learner in the contemporary learning community. To ensure entrance into the workforce once they have completed their studies, learners need to be exposed to skills that today's employers maintain will be required for future employees in order to be successful. Employers are not searching for employees who can memorize texts, lists of facts, periodic tables, or grammar rules, in fact, they are requesting that educators develop the learners':

- critical/rational, higher-order thinking skills

- problem-solving skills

- creativity and powers of reflection and innovation

- level of effective oral and written communication

- leadership qualities (for example, perseverance in an activity, effective collaboration in groupwork, integrity, initiative, and conflict resolution skills)

- general global awareness

- media literacy skills

Integration of the above-mentioned skills and contextual applications of learning in the real world build learning communities of the twenty-first century.

Today, the educational focus is on learner-centered pedagogy which is characterized by the philosophy of learner autonomy; this has resulted in changed learner and teacher roles, the focus in the classroom moving away from teachers teaching to learners acquiring meaningful knowledge, experience and a set of transferable skills which ultimately gives them ownership of their own learning. Teachers can empower their learners by:

- giving the learners the tools that will teach them to be responsible for and committed to studies/homework/projects that also need to be completed out of the classroom/school

- assigning problem-solving activities that require the use of the learners' critical/creative/higher-order reasoning skills

- offering both individual, self-paced learning experiences and cooperative, collaborative team-based activities

- providing learners with open-ended questions and problem-solving situations that serve to sharpen their creative, innovative thinking skills and allow multiple acceptable answers or solutions

- improving and meaningfully using the learners' media literacy and networking skills in activities/projects

- teaching learners to develop the power to adapt to new, different situations

- giving learners the necessary tools so that they can have more ownership of their learning 
- widening the learners' horizons through increasing their general global awareness

Socio-affective strategies and general skills_are also an important part of the innovative classroom and reflect the very essence of twenty-first century education; to exemplify, as previously mentioned, learners need to develop selfdirection by having set aims and objectives, leadership qualities to successfully initiate interactive groupwork, and critical, reflective and logical thinking to become autonomous learners. High standard moral principles and social responsibility also have a positive effect on the learners' need to develop a feeling of commitment to one's studies, which ultimately leads to self-investment in one's education.

Twenty-first century educators seek to increase the learners' level of proficiency in reasoning and critical thinking skills, offer learners activities that encourage them to learn through reflection and give the learners the knowledge, skills, and attitudes that they will need to be successful in the future. Conscientious, contemporary teachers prepare learners for self-directed learning by allowing them to make choices, and teaching them how to take responsibility for their learning; they guide learners through collaborative tasks and projects, rather than simply teach at the learners, they assess the process and various stages of a project and not only the final product/outcome, and help develop the technological competence of the learners so that they can utilize technology effectively in a collaborative learning environment.

Just as the roles of the teacher and the learner have changed in the twenty-first century, the instructional curriculum for an empowered learner requires modification.

The curriculum should:

- be meaningful, relevant, interactive and based on authentic, real-world problems

- take into account learner choice in activities, topics, type of presentation of project and assessment of project

- take into consideration individual learning differences in learners

- offer a variety of activities for differentiated instruction in order to cater for the different learning styles

- sustain the development of higher-order, critical thinking skills

- provide appropriate learning challenges and standards and tools to achieve this

- be based on learners' interests, social interactions and creativity

- allow for learner and teacher feedback, reflection, and revision, and self- and peer-assessment

\section{Conclusion}

As in many scientific fields, there are in existence several problems in the implementation of the strategies noted in this paper. One of the most pressing problems seems to be the lack of time given to several issues including oral communication of the learners in the classroom, time for necessary reflection and for two-way feedback (learner-teacher; teacher-learner), processing of information and round-table discussions.

Effective application of technology and media literacy in the classroom also requires time which is not scheduled in the curriculum. Similarly, components of twenty-first century education such as higher-order thinking, applied imagination, leadership qualities, problem-solving, cooperation/collaboration, autonomous learning and global awareness are not given the time they deserve, or, are not even recognized by some educators as vital elements in today's revolution in education, ....yet, they are obligatory skills learners need to master in order to be successful in today's complex, competitive world.

These problems are exacerbated by the lack of identification of appropriate educational standards and assessment components; teachers differ in their criteria and grades remain quite subjective, at times. The ever-present problems of writing the perfect, effective curriculum and the costly and over-ambitious objective of involving all active teachers in continuous professional development might remain actual for some time to come, however, at least teachers are required to apply the results of current research in the field of education of children, in order to meet the needs of the learners of the twenty-first century.

Learner exposure to these strategies/skills will better prepare learners for a successful future. Administrators, educators and learners need not only to think but also, to act differently; the mind-set of all involved in teaching and learning and the habits and routines of schools must change dramatically. Why continue with an educational system that does not function in the twenty-first century? Current reforms of existing teaching methods, materials and techniques in education need to be replaced by a revolution in education. We need new perspectives in teaching and learning.

Perhaps when the context-driven curricula are finally replaced by apprenticeship-like learning modules, meaningful acquisition of knowledge and skills will occur, and will be mastered by the learner from the perspective of the learner. As the world continues to change, it is urgent that teachers empower learners by reconstructing classroom strategies with skills that develop autonomy so that they may become lifelong learners. 
Education programs at the beginning of the twenty-first century will give the learner the tools that are necessary to acquire appropriate and meaningful knowledge, and to develop necessary transferable skills and a constructive, reflective attitude towards learning; the teacher will be trained through continuous professional development to effectively and successfully teach through innovative educational practices that encourage life-long learning.

\section{References}

Benson P. (2007). Autonomy in language teaching and learning. Language Teaching;40:21-40.

Benson, P. \& Voller, P. (1997). Autonomy and Independence in Language Learning. London: Longman.

Bown, L. (2000) Lifelong Learning: ideas and achievements at the threshold of the twenty-first century. Compare, 30/3: 341-351

Brandt, Ronald S. (2000) Education in a New Era. Alexandria, VA: Association for Supervision and Curriculum Development

Brown, H. D. (1987). Principles of Language Learning and Teaching. Englewood Cliffs, JC: Prentice Hall.

Dam, L. (1990). Learner Autonomy in Practice. In Gathercole, I. (ed.). 1990, p. 16. CILT. Great Britain: Bourne Press.

Gardner, H. (2000). Intelligence Reframed: Multiple Intelligences for the Twenty-first Century. Basic Books, New York

Hegarty, S, (2000) Teaching as a knowledge-based activity. Oxford Review of Education, 26 (3/4), 451-465

Holec, H. (1981). Autonomy in foreign language learning (first published 1979, Strasbourg: Council of Europe). Oxford:Pergamon.

Hung, D. (2003). Supporting Current Pedagogical Approaches with Neuroscience Research. Journal of Interactive Learning Research, 14(2), 129-155. Norfolk, VA: AACE. Retrieved June 30, 2014 from http://www.editlib.org/p/1199.

Johnson, Pardesi, and Paine. (1990). Autonomy in Our Primary School. In Gathercole, I. 1990. Autonomy in Language Learning. CILT: Bourne Press.

Lea, S. J., D. Stephenson, and J. Troy (2003). Higher Education Students' Attitudes to Student Centred Learning: Beyond 'educational bulimia'. Studies in Higher Education 28(3), 321-334.

Little, D. (1991). Learner Autonomy. 1: Definitions, Issues and Problems. Dublin: Authentik.

Moss, D. M. (2005) Portrait of a Profession: Teaching and Teachers in the Twenty-first Century Greenwood Publishing Group Portsmouth, $\mathrm{NH}$

O'Malley, J. M. and Chamot, A. V. (1990). Learning Strategies in Second Language Acquisition. London: Macmillan.

Samuels, B. M. (2009). Can differences between education and neuroscience be overcome by Mind, Brain, and Education? Mind, Brain, and Education, 3(1), 45--53.

Skehan, P. (1998). A Cognitive Approach to Language Learning. Oxford: OUP.

Wenden, A. (1998). Learner Strategies for Learner Autonomy. Great Britain: Prentice Hall. 